Available online on 15.05.2020 at jddtonline.info
Open Access to Pharmaceutical and Medical Research
unrestricted non-commercial use, provided the original work is properly cited

Open Access

Research Article

\title{
Acute Oral Toxicity Studies of the Crude Extract of Endophytic Fungi Isolated from Annona senegalensis Pers
} \author{
Chinedum. ${ }^{2}$, Attama, A. Anthony. ${ }^{2}$ \\ ${ }^{1}$ Department of Pharmaceutical Microbiology and Biotechnology, University of Nigeria, Nsukka, Nigeria \\ 2 Department of Pharmaceutics, University of Nigeria, Nsukka, Nigeria \\ ${ }^{3}$ Department of Pharmaceutics and Pharmaceutical Technology, University of Uyo, Nigeria
}

Onah, A. Ikechukwu. ${ }^{*}$, Kenechukwu, C. Franklin' ${ }^{2}$, Berebon, P. Dinebari ${ }^{1}$, Agboke, A. Akeem. ${ }^{3}$ Ibezim, E.

\begin{abstract}
Establishment of safety and toxicity profiles of metabolites of endophytic organisms from known medicinal plants are crucial in their pharmacological and biological applications. The aim of this study was to evaluate the oral acute toxicity (LD50) of crude extract of endophytic fungi isolated from Annona senegalensis Pers. The endophytic fungal metabolite was extracted with ethyl acetate. The LD 50 was estimated following the method described by Lorke. Three dose levels $(10,100$, and $1000 \mathrm{mg} / \mathrm{kg})$ of the crude extract were administered to three mice each for the first phase using oral gavage needle in a single dose disposable syringe. The animals were observed for possible deaths or other side effects of the test substance in each group within 24 hours of the treatment. In the second phase, which was deduced from the first phase, eight mice were sub-divided into four groups of two mice each and they were treated with doses of 1200, 1600, 2900 and 5000 mg/kg orally. They were also observed within 24 hours and final $\mathrm{LD}_{50}$ value was determined. Results showed that the endophytic fungal extract exhibited no mortality or any histological defect in the liver tissues of the mice. More so, the immunological parameter tested showed significant increase in neutrophils and lymphocytes relative to the control in all the fungal isolates. Additionally, the $\mathrm{LD}_{50}$ for the crude metabolites was $>5000 \mathrm{mg} / \mathrm{kg}$ This study has revealed that crude extract of endophytic fungi isolated from Annona senegalensis Pers did not show oral acute toxicity in mice. Further studies will evaluate long term-toxicity of the crude extract.
\end{abstract}

Keywords: Endophytes, LD50, Annona senegalensis, Metabolites, Fungi

Article Info: Received 11 March 2020; $\quad$ Review Completed 24 April 2020; $\quad$ Accepted 04 May 2020; Available online 15 May 2020

Cite this article as:

Onah AI, Kenechukwu CF, Berebon PD, Agboke AA Ibezim EC, Attama A A, Acute Oral Toxicity Studies of the Crude Extract of Endophytic Fungi Isolated from Annona senegalensis Pers, Journal of Drug Delivery and Therapeutics. 2020; 10(3):207216 http://dx.doi.org/10.22270/jddt.v10i3.4052

*Address for Correspondence:

Onah, A. Ikechukwu, Department of Pharmaceutical Microbiology and Biotechnology, University of Nigeria, Nsukka, Nigeria

\section{INTRODUCTION}

Man has over time relied on plants for food and medicines. [1, 2] The rationale for the use of these plants by man for treatment of different disease conditions has been variously described as traditional, economic, accessibility and effectiveness. [3, 4, 5] Annona senegalensis Pers. is one of the foremost plants used in West Africa with documented evidence of its use traditionally in the treatment of malaria, trypanosomiasis, snake bite, body pain, fever, urinary tract infection, convulsion hepatitis e t c. [6,7] Some of these plants known for their medicinal values are consistently being consumed for immediate health challenges without recourse to any established safety or scientific protocols. ${ }^{[1,2]}$ This has however, placed some consumer of these medicinal products at high risks of acute or chronic toxicities. Acute toxicity testing provides baseline toxicological data that can be used to describe an agent or substance based on its possible health risk. [8] It also describes the adverse toxicological effects of an agent that occur either from a single exposure or from multiple exposures in a short period of time (usually less than 24 hours) [8,9]. In undertaking acute toxicity testing, various routes of exposure such as oral, dermal or inhalational are often explored in mice which serve as the most common animal model in toxicity studies. [8, 10] In a related development, the exploration of microbial diversity of medicinal plants as new frontiers in searching for novel compounds against human diseases has attracted interest towards the endophytic research [11]. In past years, endophytic studies were not eliciting so much interest among the scientific community probably due to focus on plant extract exploration. However, owing to recent 
discoveries of their high potent bioactive compounds and diverse structural complexity, which when extracted as lead compound will find useful application in medicine, chemical industry and Agriculture, endophytic metabolites are keenly explored [12, 13, 14]. To the best of knowledge, the oral acute toxicity studies of the crude extract of endophytic fungi isolated from Annona senegalensis Pers has not been documented. Consequently, this research aims at evaluating the acute oral toxicity of crude extract from endophytic fungi isolated from Annona senegalensis Pers using the method described by Lorke [15].

\section{MATERIALS AND METHOD}

\subsection{Materials}

The materials used in this study are: dimethyl sulfoxide (DMSO) and ethyl acetate (Sigma Aldrich U.K), absolute ethanol and ethidium bromide (Bio-Rad laboratories, United States), sodium hydroxide (Randox laboratory limited, United Kingdom), nutrient agar and nutrient broth (Titan Biotech. Ltd; India), Mueller Hinton Agar and Peptone Water (HiMedia Labs. Ltd; Mumbai India). Distilled water was obtained from lion table water (University of Nigeria Nsukka). All other reagents procured were analytical grade and were used without further purification.

\subsection{Sample collection and authentication}

Various plant parts of Annona senegalensis used in this study (root, stem and leaves) were collected from a non-diseased, mature plant in September 2017, at Mbu-Akpoti, in Isi-Uzo local Government Area of Enugu State Nigeria. The freshly collected plant samples were duly identified by a taxonomist, Mr. Alfred Ozioko, a retired staff of Botany Department, University of Nigeria Nsukka. Further authentication of the samples was done by a botanist Mr. Onyeukwu Chijioke John of Plant Science and Biotechnology (former Botany) Department, University of Nigeria, Nsukka. The samples were assigned a voucher number UNH NO 9a and deposited at the herbarium collection center of Plant Science and Biotechnology Department (Botany), University of Nigeria. Ethical clearance approval (DOR/UNN/19/00029) was equally sought and obtained from office of the ViceChancellor, Directorate of Research, University of Nigeria.

\subsection{Cultivation and Isolation of endophytic fungi.}

The methods of Okezie et al [16] were adopted with slight modifications. Here, freshly harvested samples (roots, stems and leaves) were washed thoroughly in running tap water followed by sterile double distilled water before processing. To eliminate epiphytic microorganisms, all the samples were subjected to four step surface sterilization which includes washing under running tap water-ethanol-sodium hypochlorite-distilled water. The samples were washed in running tap water, after which they were further immersed in $70 \%$ ethanol for $3 \mathrm{~min}$ and washed twice with distilled water. In addition, the already washed samples were again immersed in sodium hypochlorite solution (4\%) for $5 \mathrm{~min}$ and washed thoroughly thrice in distilled water and then rinsed in $70 \%$ ethanol for $3 \mathrm{~min}$, before a final rinse in sterilized double distilled water. The washed samples were dried in a laminar flow chamber on a sterile filter paper. Sterile knife was used to cut the samples to approximately 1 $\mathrm{cm}$ lengths. Segments (a total of 30 at three to six segments per Petri dish) of samples were inoculated on previously sterilized media (malt extract agar) incorporated, with chloramphenicol, $500 \mathrm{mg} / \mathrm{L}$ in Petri dishes. The cut end of the material was made to contact the media. The Petri dishes were properly sealed using parafilms, then incubated at 25 ${ }^{\circ} \mathrm{C}$ and the plates were checked on alternate days. After 7 days, hyphal tips of actively growing fungi from the plant material were then sub-cultured in other sterile Malt Extract Agar plates and were incubated for 5 to 7 days and the purity of the cultures was checked periodically. Sub-culturing was done at an interval of two weeks to maintain the pure cultures. For studying the cultural characteristics, the fungi were grown on Malt Extract Agar medium. Cultural characteristics such as color, nature of growth of the colony and texture were determined by visual observation.[17] The maximum growths of the fungi were also observed on Malt Extract Agar, whereas, for the production of metabolites, the starting material was taken from freshly sub-cultured plates.

\subsection{Purification of fungi isolate}

To prepare inocula for fermentation studies, cultivation of hyphae/mycelium to obtain pure cultures was done. The hyphal tips of fungi, emerging out of the previously subcultured fungi was again sub-cultured by picking the hyphal tip, placing on a fresh MEA and incubating at $25^{\circ} \mathrm{C}$ for 7 days. All transfers were done aseptically, to ensure purity of isolates. After inoculation, it was discovered that the root and leaf blades of the plant under study gave three and one respectively making a total of four fungi isolated during the course of this study whereas, the stem did not show any form of growth after sufficient period of incubation.

\subsection{Fermentation of pure isolates}

Local rice was used as the fermentation medium. A $100 \mathrm{~g}$ quantity of the local rice was weighed into a sterile conical flask, $200 \mathrm{~mL}$ of sterile water was added onto it, and the content sterilized appropriately at $121{ }^{\circ} \mathrm{C}$ for $30 \mathrm{~min}$, and then allowed to cool properly.

Thereafter, segments were aseptically cut from the actively growing pure isolates on MEA and inoculated into the already sterilized local rice fermentation medium contained in a $500-\mathrm{mL}$ Erlenmeyer flask, which was properly sealed and kept on the shelf. The fermentation process was allowed for 21 days at $30{ }^{\circ} \mathrm{C}$ under static conditions.

\subsection{Extraction of Fungal metabolites}

The fermentation process was stopped by the addition of the extraction solvent (ethyl acetate) and each of the fermented media in the sterile Erlenmeyer flasks was made homogeneous. Here, fungal biomass including the medium were cut into small lumps using a sterile glass rod and the mixture was homogenized with $500 \mathrm{~mL}$ of ethyl acetate in 1L Erlenmeyer flasks, shaken occasionally for 2 days and then filtered using Whatman filter paper (size: $188 \mathrm{~mm}$ ). The filtrate was concentrated at $50{ }^{\circ} \mathrm{C}$ under reduced pressure using a rotary evaporator. The concentrated extract was further left to evaporate to dryness in a desiccator containing sodium hydroxide. Then, the corresponding extracts (RT1, RT2, RT3 and LB1) were weighed and their respective percentage yields recorded in milligram. After evaporation, the dried fungal extracts were reconstituted in dimethyl sulphoxide (DMSO) and subjected to biological studies.

\subsection{Experimental animals}

Seventeen germ-free and age-matched adult male mice (Mus musculus) were used for the study. The animals were procured from TwinVet Resource ${ }^{\circledR}$ in Nsukka, Enugu State, Nigeria. The animals were taken to the research facilities of the Department of Veterinary Anatomy, Faculty of Veterinary Medicine, University of Nigeria, Nsukka. They were kept there and provided with adequate feed and water for a period of seven days before the commencement of the studies. 


\subsection{Ethics statement}

The protocol was conducted in compliance with the Guide for the Care and Use of Laboratory Animals, 8th edition, 2011. Animal sacrifice was performed by euthanasia, according to the University of Nigeria guidelines on Euthanasia, and efforts were made to minimize animal suffering.

\subsection{Experimental design}

Seventeen healthy adult male mice were weighed and their sexes determined. The acute oral toxicity $\left(\mathrm{LD}_{50}\right)$ was estimated following the method described by Lorke. [15] Dose levels of 10,100 , and $1000 \mathrm{mg} / \mathrm{kg}$ were administered to three mice each for the first phase. The animals were observed for possible deaths or other side effects associated with the test substance in each group within $24 \mathrm{~h}$ of the treatment. In the second phase, which was deduced from the first phase, eight mice were grouped into four groups of two rats each and they were treated with doses of 1200, 1600 , 2900 and $5000 \mathrm{mg} / \mathrm{kg}$ orally respectively. They were also observed for $24 \mathrm{~h}$ as in the first phase, and final $\mathrm{LD}_{50}$ value, determined.

\subsection{Euthanasia}

Each mouse was sacrificed by euthanasia. Euthanasia was achieved by injection of $1 \mathrm{ml}$ of ketamine by intramuscular administration, using a syringe and hypodermic needle.

\subsection{Histological preparation}

Following euthanasia, the liver from each mouse was harvested and fixed/preserved in $10 \%$ neutral-buffered formalin before subjection to tissue processing procedures for the preparation of permanent mount of each tissue as described by Sofowora. [18] The tissues were dehydrated through various grades of alcohol $(60,70,80$, and $90 \%)$ with a final bath in $100 \%$ ethanol (twice) to ensure total elimination of moisture. Clearing was performed in toluene in order to raise its refractive index to that of glass (1.5) to enable transparency of the cellular inclusions. The processes of infiltration and embedding were performed using liquid paraffin and molten paraffin wax in an L-shaped mould, respectively. Sections were made using Rotary Microtome and the Hot plate method was used for mounting specimens onto slides. Staining of tissues was performed using hematoxylin and eosin stains. Canada balsam was used in mounting the tissues.

\subsection{Light microscope examination}

The Leica binocular light microscope was used to examine the histomorphological characteristics of the liver of the treated mice. Photomicrographs were captured using a Moticam Images Plus 2.0 digital camera (Motic China Group Ltd) attached to the Leica binocular light Microscope.

\subsection{Effects of graded doses of the fungal metabolites on some hematological parameters of the mice.}

\subsubsection{Haemoglobin estimation.}

This was carried out using standard procedure as described by Ochei and Kolhatkan. [19] Well mixed venous blood (20 $\mu$ l) was added to $5 \mathrm{ml}$ of Drabkins solution in a test tube to give a dilution of $(1: 250)$. This was mixed and allowed to stand for $10 \mathrm{~min}$ at room temperature. The absorbance was calorimetrically determined at 540 nanometer using Drabkins solution as blank. The absorbance reading was multiplied by a factor of 36.8 to give the actual haemoglobin value.

\subsubsection{Determination of Packed Cell Volume (PCV)}

This was carried out using standard haematological procedure as described by Ochei and Kolhatkar. [19] Well mixed anti-coagulated blood was aspirated into a capillary tube with one end sealed with plasticine. The tube was spun in a haematocrit centrifuge for 5 min and then read off a PCV reader.

\subsubsection{Determination of White Blood Cell (WBC)}

This was done using standard haematological procedure as described by Ochei and kolhatkar. [19] Well mixed anticoagulated blood was diluted 1:20 with Turks solution (2 $\%$ glacial acetic acid) in a test tube. This was loaded into an improved Neubauer counting chamber. Appropriate squares were counted and added up to determine the WBC.

\subsubsection{Determination of Red Blood Cell (RBC)}

This was done using standard haematological procedure as described by Ochei and Kolhatkar. [19]. Well mixed anticoagulated blood was diluted 1:20 with $10 \%$ Na2CO3 solution. The mixture was loaded into an improved Neubauer counting chamber. Appropriate squares were added up to determine the total red cell count.

\subsection{Effects of the graded doses on biochemical parameters of rats}

In this section, the biochemical parameters were determined according to various methods described by to Randox Laboratories Limited [20] as follows:

\subsubsection{Determination of creatinine}

Briefly, equal volumes of picric acid and sodium hydroxide were mixed to get a working reagent at 25 to $30{ }^{\circ} \mathrm{C}$. Using two cuvettes $(1 \mathrm{~cm}$ light path) one each for standard and sample, $1 \mathrm{ml}$ of working reagent was added into each cuvette. $100 \mu \mathrm{l}$ of standard and sample (EDTA plasma) solutions were added to their respective cuvettes and each mixed appropriately. After $30 \mathrm{sec}$, the absorbance A1, of standard and sample were read at $510 \mathrm{~nm}$. Exactly $2 \mathrm{~min}$ later, the absorbance $\mathrm{A} 2$, was read of the standard and sample.

\section{Concentration of creatinine in serum or plasma $=$ $\frac{\Lambda \text { A sample }}{\Lambda \text { A standard }} \mathrm{X}$ std conc $(\mu \mathrm{mol} / \mathrm{l}) \quad$ equation 1}

\subsubsection{Determination of Albumin}

A $0.01 \mathrm{ml}$ of distilled water was pipetted into a cuvette containing $3.00 \mathrm{ml}$ of BCG reagent and the absorbance read off as blank. Then, $0.01 \mathrm{ml}$ of serum and $0.01 \mathrm{ml}$ of standard reagent were pipetted into their respective cuvettes containing $3.0 \mathrm{ml}$ BCG reagent and mixed for $5 \mathrm{~min}$ at $25^{\circ} \mathrm{C}$. The absorbance of the sample (A sample) and that of the standard (A standard) were measured against the blank. Calculation of the concentration of the albumin in the sample is as follows:

$$
\frac{\text { A sample }}{\text { A standard }} \times \text { concentration of standard }(\mathrm{g} / \mathrm{l}) \text {. equation } 2
$$

Where A sample = Absorbance of sample, A standard = Absorbance of standard.

\subsubsection{Determination of Total Protein}

In this procedure, blank solution was prepared by pipetting $0.02 \mathrm{ml}$ of distilled water into a cuvette containing $1.0 \mathrm{ml}$ Biuret solution. Next, $0.02 \mathrm{ml}$ of the standard protein and sample each was pipetted in their respective cuvettes containing $1.0 \mathrm{ml}$ of Biuret solution and mixed for $30 \mathrm{~min}$ at $25{ }^{\circ} \mathrm{C}$. The absorbance of each solution in their respective 
cuvettes was recorded at $530 \mathrm{~nm}$ against the blank. The Total Protein was calculated as:

$$
\frac{\text { A sample }}{\text { A standard }} \text { x concentration of standard (g/l) equation } 3
$$

Where A sample $=$ Absorbance of sample, A standard $=$ Absorbance of standard.

\subsubsection{Determination of Alkaline Phosphatase}

Principle: p-nitrophenyphospate $+\mathrm{H}_{2} \mathrm{O}$----->Phosphate + pnitrophenol

In summary, $0.01 \mathrm{ml}$ of sample was pipetted into a cuvette containing $0.5 \mathrm{ml}$ of reagent (diethanolamine buffer, $\mathrm{MgCl}_{2}$ and p-nitrophenylphosphate), mixed and the initial absorbance read at $405 \mathrm{~nm}$ and $30{ }^{\circ} \mathrm{C}$. The timer was restarted simultaneously and readings were taken after 1,2 and $3 \mathrm{~min}$.

\section{Calculation of the ALP in $U / \mathrm{l}=2760 \mathrm{X} \Delta \mathrm{A}$ at $405 \mathrm{~nm} / \mathrm{min}$.} equation 4

Where $\Delta \mathrm{A}=$ change in absorbance; initial absorbanceabsorbance at time $\mathrm{T}$.

\subsubsection{Determination of Aspartate Aminotransferase}

This was carried out by measurement against sample blank as described earlier. [20] Two test tubes containing $5.0 \mathrm{ml}$ of reagent 1 (phosphate buffer $100 \mathrm{mmol} / \mathrm{l}$ at $\mathrm{pH} 7.4$, Laspartate $100 \mathrm{mmol} / \mathrm{l}$ and $\alpha$ - oxoglutarate $2 \mathrm{mmol} / \mathrm{l}$ ) were labelled sample and sample blank respectively. Further, 0.1 $\mathrm{ml}$ of serum (sample) was pipetted into the sample test tube. The tubes were mixed and incubated for $30.0 \mathrm{~min}$ at $37 \mathrm{o}$. Again, $5.0 \mathrm{ml}$ of reagent 2 (2,4- dinitrophenyl hydrazine 2.0 $\mathrm{mmol} / \mathrm{l}$ ) was added to each test tube while $0.1 \mathrm{ml}$ of serum was added to sample blank test tube. The above tubes were stirred and allowed to stand for exactly $20 \mathrm{~min}$ at $25^{\circ} \mathrm{C}$. Five milliliters of sodium hydroxide was added to each tube and allowed to mix thoroughly and then the absorbance of the sample (A sample) at $546 \mathrm{~nm}$ against the sample blank was read after $5.0 \mathrm{~min}$.

\subsubsection{Determination of Alanine Aminotransferase}

This was determined by measurement against sample blank as described by Randox Laboratories Ltd. [20] Two test tubes containing $5.0 \mathrm{ml}$ of reagent 1 (phosphate buffer $100 \mathrm{mmol} / \mathrm{l}$ at $\mathrm{pH} \mathrm{7.4,} \mathrm{L-alanine} 200 \mathrm{mmol} / \mathrm{l}$ and $\alpha$ - oxoglutarate $2 \mathrm{mmol} / \mathrm{l}$ ) were labelled as sample and sample blank respectively. Further, $0.1 \mathrm{ml}$ of serum (sample) was pipetted into the sample test tube. The content of the tube was mixed and incubated for $30 \mathrm{~min}$ at $37^{\circ} \mathrm{C}$. Again, $5.0 \mathrm{ml}$ of reagent 2 (2, 4- dinitrophenyl hydrazine $2.0 \mathrm{mmol} / \mathrm{l}$ ) was added to each test tube while $0.1 \mathrm{ml}$ of serum was added to sample blank test tube. The above tubes were stirred and allowed to stand for exactly $20 \mathrm{~min}$ at 25 o C. Five milliliter of sodium hydroxide was added to each tube and allowed to mix thoroughly and then the absorbance of the sample (A sample) at $546 \mathrm{~nm}$ against the sample blank was read after 5 $\min$.

\subsection{Determination of Differential white cell count}

This was carried out according to the method described by Cheesbrough [21]. A drop of anticoagulated venous blood was placed on the end of a clean dry slide. A clean smooth-edged spreader held at an angle of 30 was used to spread the drop of blood, making a film of about $40-50 \mathrm{~mm}$. The film was immediately air-dried by waving it back and forth and when completely dried, the film was fixed by placing 1 to 2 drops of moisture free methyl alcohol on the film and allowing it to dry on a staining rack. The dry blood film was covered with 3 drops of undiluted Leishmans reagent (no 48) and 6 drops of pH 6.8 buffered water (reagent no 20) was equally added and mixed thoroughly using plastic bulb pipette. The mixed stain was allowed to stay for $10 \mathrm{~min}$ and then washed off with tap water. The back of the slide was wiped clean and made to stand on staining rack for the smear to dry. A drop of immersion oil was placed on the lower third of the blood film and covered with a clean cover glass. The film was examined microscopically by focusing on the cells using $10 \mathrm{x}$ objective with the condenser iris closed sufficiently to see the cells clearly. Moving to a part of the film where the red cells overlap, the 40x objective was brought in and the iris diaphragm was opened more. Systematically, the blood film was examined and the different white cells in each field were counted using automatic differential cell counter. The absolute number of each white cell type was calculated by multiplying the number of each cell counted (expressed as decimal fraction) by the total WBC count.

\subsection{Statistical analysis}

Results were analyzed using Statistical Package for Social Science (SPSS-20, for windows) software and presented as Mean \pm Standard error of mean (SEM) of sample replicates ( $n$ $=3$ ). Significant differences between control and treatment groups were compared using one-way analysis of variance (ANOVA) followed by Post hoc Dunnett (2-sided) test. P < 0.05 was considered to be statistically significant.

\subsection{RESULTS}

Table 1 present results of the oral acute toxicity testing of the endophytic fungal metabolites from Annona senegalensis on mice. Incidentally, none of the animals died within the 24 hours of the experiment, no lesion or any sign of inflammation was noticed on the liver after histopathological analysis. The biochemicals as well as the haematological parameters were also observed. Also, it was deduced from the result that the $\mathrm{LD}_{50}$ of the metabolites were above the tested doses. 
Table 1: acute oral toxicity studies of various doses of endophytic fungal metabolites on mice.

\begin{tabular}{|c|c|c|c|c|c|}
\hline Group & Dose mg/kg & N/D & \% Mortality & Observation Period (h) & Symptoms of toxicity \\
\hline & & Metabolite & from $\quad$ RT1 & & \\
\hline 1 & 10 & $3 / 0$ & 0 & 24 & No sign of toxicity observed \\
\hline 2 & 100 & $3 / 0$ & 0 & 24 & No change observed \\
\hline 3 & 1000 & $3 / 0$ & 0 & 24 & No inactivity \\
\hline 4 & 1600 & $2 / 0$ & 0 & 24 & Initial restlessness \\
\hline 5 & 2900 & $2 / 0$ & 0 & 24 & Sluggish movement \\
\hline 6 & 5000 & $2 / 0$ & 0 & 24 & Initial restlessness \\
\hline \multirow[t]{2}{*}{7} & control & $2 / 0$ & 0 & 24 & No change \\
\hline & & Metabolite & From & RT2 & \\
\hline 1 & 10 & $3 / 0$ & 0 & 24 & No sign of toxicity \\
\hline 2 & 100 & $3 / 0$ & 0 & 24 & No changes observed \\
\hline 3 & 1000 & $3 / 0$ & 0 & 24 & No toxicity \\
\hline 4 & 1600 & $2 / 0$ & 0 & 24 & No changes \\
\hline 5 & 2900 & $2 / 0$ & 0 & 24 & No sign of toxicity \\
\hline 6 & 5000 & $2 / 0$ & 0 & 24 & Initial dullness \\
\hline \multirow[t]{2}{*}{7} & control & $2 / 0$ & 0 & 24 & No changes \\
\hline & & Metabolite & From & RT3 & \\
\hline 1 & 10 & $3 / 0$ & 0 & 24 & No changes observed \\
\hline 2 & 100 & $3 / 0$ & 0 & 24 & No toxicity \\
\hline 3 & 1000 & $3 / 0$ & 0 & 24 & Staggered movement \\
\hline 4 & 1600 & $2 / 0$ & 0 & 24 & Calm \\
\hline 5 & 2900 & $2 / 0$ & 0 & 24 & Initial scratching of mouth \\
\hline 6 & 5000 & $2 / 0$ & 0 & 24 & Sluggish movement \\
\hline \multirow[t]{2}{*}{7} & control & $2 / 0$ & 0 & 24 & \\
\hline & & Metabolite & From & LB1 & \\
\hline 1 & 10 & $3 / 0$ & 0 & 24 & No toxicity \\
\hline 2 & 100 & $3 / 0$ & 0 & 24 & No toxicity \\
\hline 3 & 1000 & $3 / 0$ & 0 & 24 & No toxicity \\
\hline 4 & 1600 & $2 / 0$ & 0 & 24 & No changes \\
\hline 5 & 2900 & $2 / 0$ & 0 & 24 & No changes \\
\hline 6 & 5000 & $2 / 0$ & 0 & 24 & Dullness of animal \\
\hline 7 & control & $2 / 0$ & 0 & 24 & No change \\
\hline
\end{tabular}

N/D: No of dead mice.

RT1

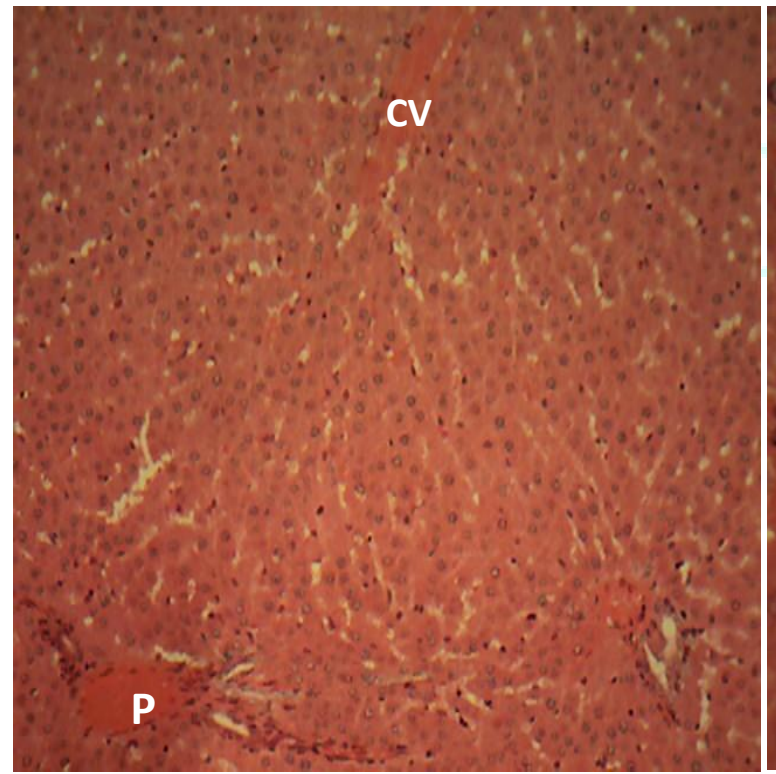

(A)

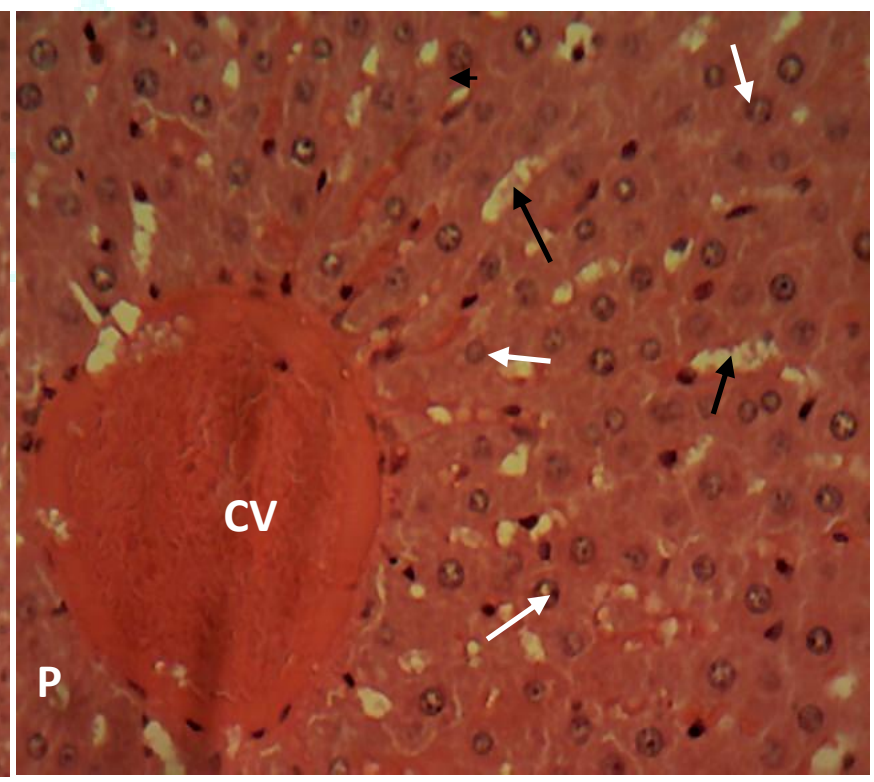

(B)

Figure 1:A and B represent front and back views of sections of the liver collected from the mice given RT1.This group showed normal hepatic histomorphology for laboratory rodents. The tissue sections showed normal hepatic lobules made up of normal hepatocytes arranged in interconnecting hepatic cords (Black arrows) around the central veins (CV). The hepatic cords are separated by the hepatic sinusoids (white arrows), and radiate towards the periphery of the hepatic lobules (portal areas; P), where they meet with the components of the portal triads (branches of the hepatic artery (HA), hepatic vein (HV) and bile duct (BD)) which are suspended in loose connective tissue matrix. H\&Ex100; x400 
RT2

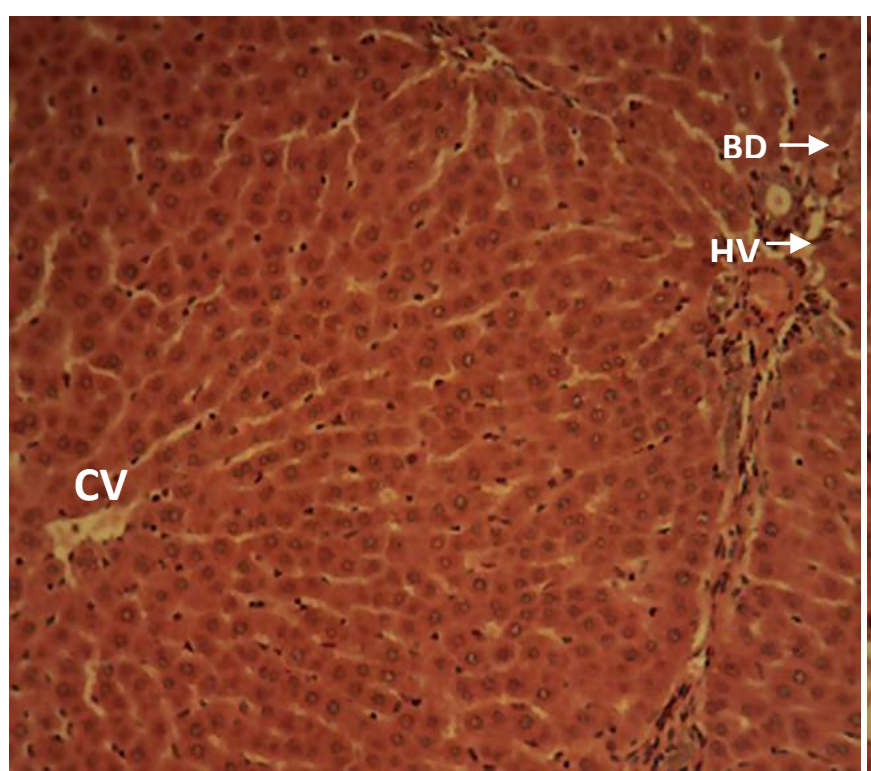

(C)

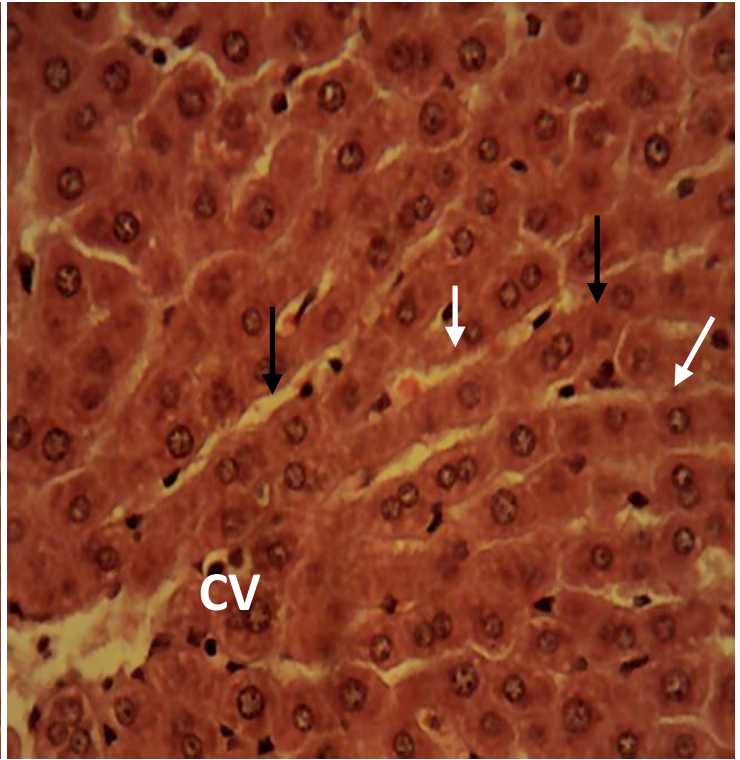

(D)

Figure 2: $\mathrm{C}$ and D represent front and back views of sections of the liver collected from the mice given RT2. Sections of the Liver collected from the animals in this group showed the normal histomorphological features of liver of laboratory mice. See details above. Note the components of the Portal areas; Bile ductule (BD), Hepatic venule (HV). H\&Ex160; 4

\section{RT3}
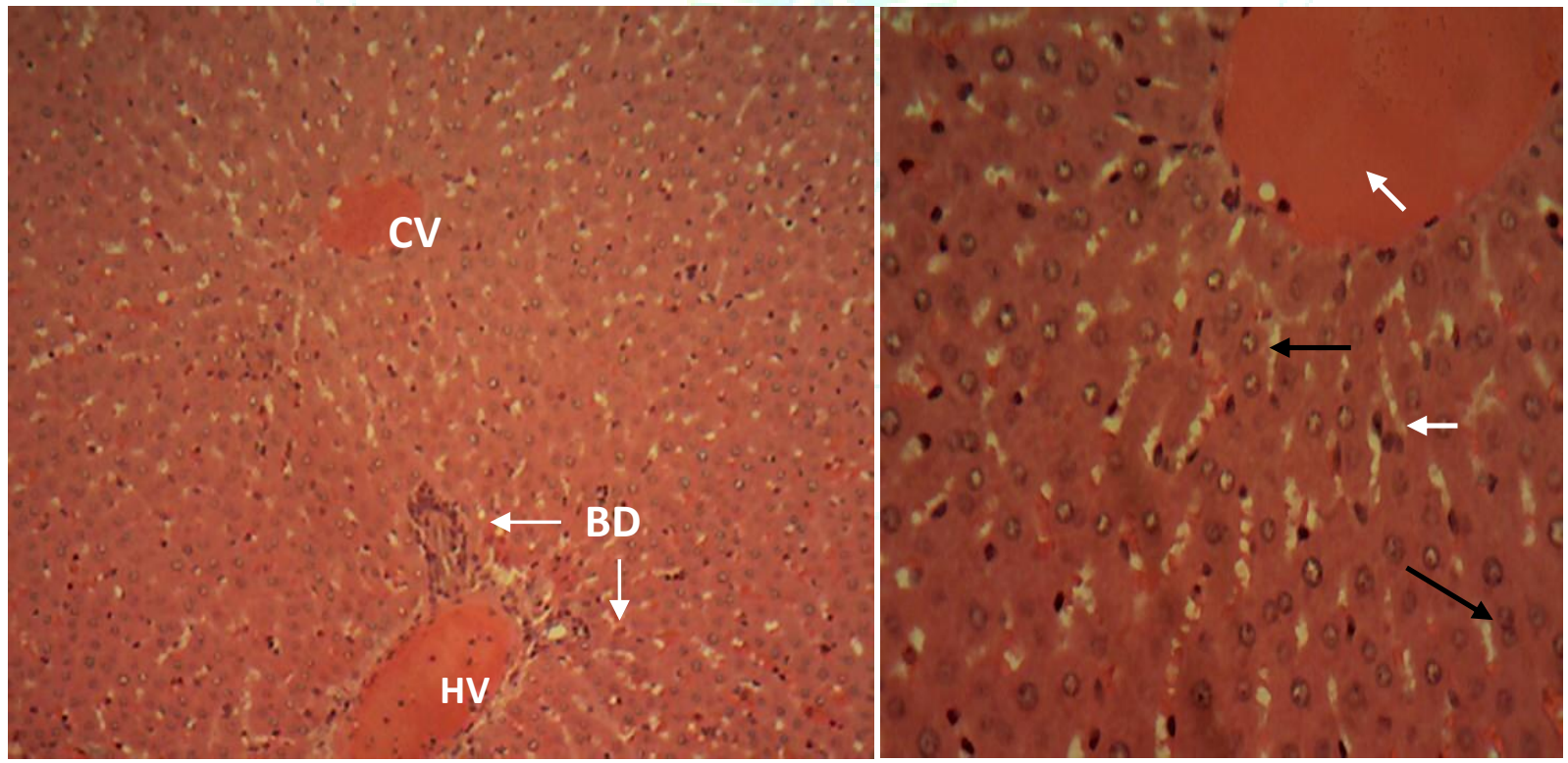

(E)

(F)

Figure 3: $\mathrm{E}$ and F represent front and back views of sections of the liver collected from the mice given RT3. Sections of the Liver collected from the animals in this group showed the normal histomorphological features of the liver of mice. See details above. H\&Ex160; x400. 
LB1
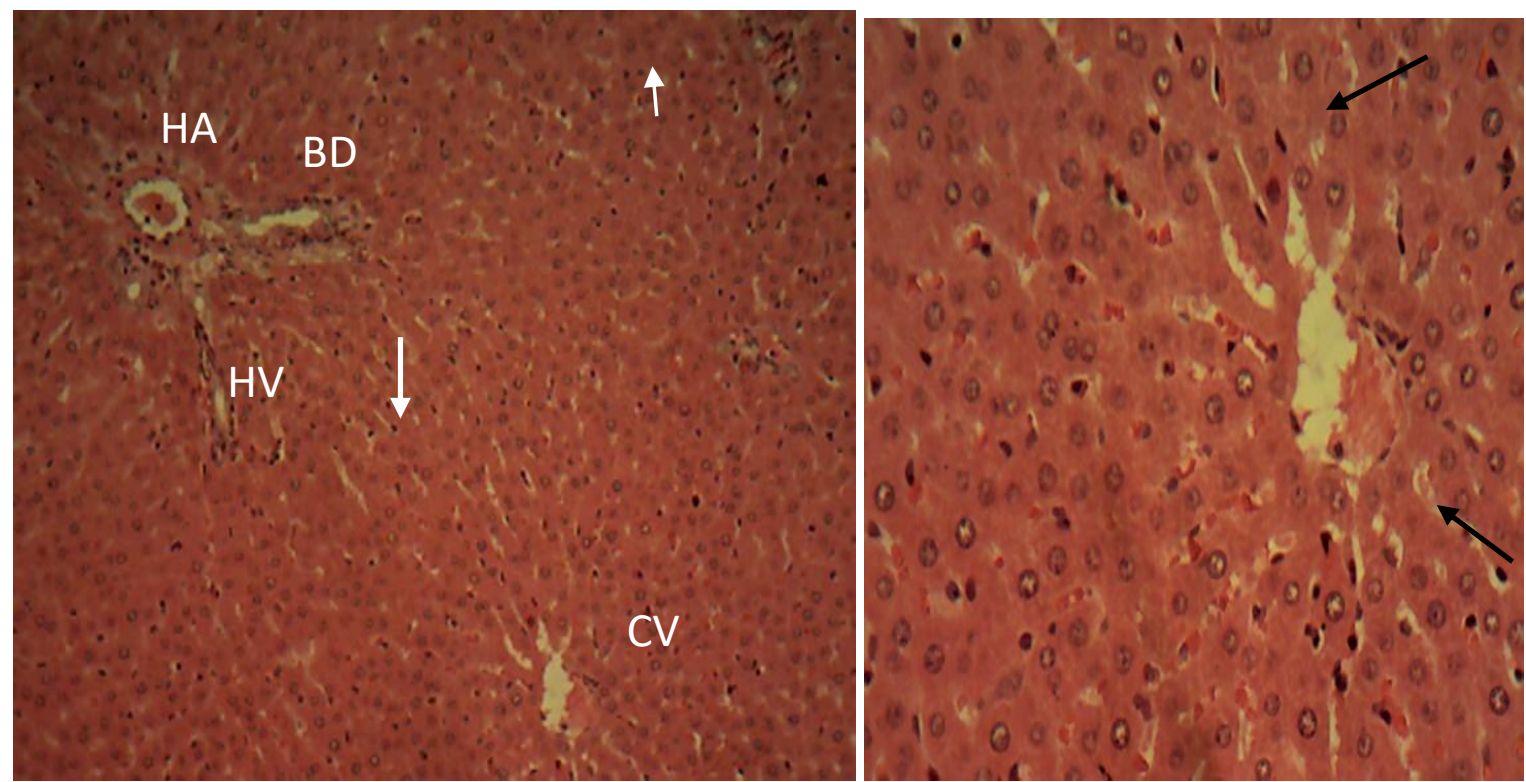

(G)

(H)

Figure 4:G and $\mathrm{H}$ represent front and back views of sections of the liver collected from the mice given LB1 Sections of the Liver collected from the animals in this group showed the normal histomorphological features of liver of mice. See details above. Note the components of the Portal areas; Hepatic arteriole (HA), Hepatic venule (HV) and Bile ductule (BD). H\&E x100; x400.

Table 2: Effects of the graded doses of the fungal metabolites on hematological parameters of rats

\begin{tabular}{|c|c|c|c|c|c|c|}
\hline $\begin{array}{l}\text { Treatm } \\
\text { ent }\end{array}$ & $\begin{array}{l}\text { Dose } \\
\text { (mg/kg) }\end{array}$ & PCV (\%) & RBC (x1012/L) & WBC( $\left.\times 10^{9} / \mathrm{L}\right)$ & PLT (x109/L) & HB (g/dl) \\
\hline \multirow[t]{7}{*}{ RT1 } & Control & $33.00 \pm 1.15$ & $3.80 \pm 0.12$ & $7800.00 \pm 0.00$ & $200.00 \pm 0.58$ & $11.90 \pm 0.06$ \\
\hline & 10 & $38.00 \pm 1.15^{*}$ & $4.10 \pm 0.06$ & $8400.00 \pm 0.00$ & $195.00 \pm 1.15^{* *}$ & $13.10 \pm 0.00^{* * *}$ \\
\hline & 100 & $41.00 \pm 0.58^{* * *}$ & $4.20 \pm 0.17$ & $7900.00 \pm 0.00$ & $210.00 \pm 1.15^{* * *}$ & $15.70 \pm 0.12^{* * *}$ \\
\hline & 1000 & $39.00 \pm 0.58^{* *}$ & $3.60 \pm 0.00$ & $7200.00 \pm 0.00$ & $200.00 \pm 0.00$ & $14.20 \pm 0.06^{* * *}$ \\
\hline & 1600 & $44.00 \pm 0.58^{* * *}$ & $3.90 \pm 0.06$ & $6400.00 \pm 0.00$ & $190.00 \pm 1.15^{* * *}$ & $13.70 \pm 0.00^{* * *}$ \\
\hline & 2900 & $48.00 \pm 1.15^{* * *}$ & $4.60 \pm 0.23^{* *}$ & $6100.00 \pm 0.00$ & $215.00 \pm 1.15^{* * *}$ & $16.40 \pm 0.00^{* * *}$ \\
\hline & 5000 & $36.00 \pm 1.15$ & $4.40 \pm 0.06^{*}$ & $5400.00 \pm 0.00$ & $190.00 \pm 0.56^{* * *}$ & $18.20 \pm 0.12^{* * *}$ \\
\hline \multirow[t]{7}{*}{ RT2 } & Control & $33.00 \pm 0.00$ & $3.80 \pm 0.12$ & $7800.00 \pm 0.00$ & $200.00 \pm 0.00$ & $11.90 \pm 0.06$ \\
\hline & 10 & $33.00 \pm 0.58$ & $4.00 \pm 0.12$ & $8100.00 \pm 0.00$ & $200.00 \pm 1.73$ & $12.10 \pm 0.12$ \\
\hline & 100 & $35.00 \pm 1.15$ & $3.90 \pm 0.12$ & $8400.00 \pm 0.00$ & $195.00 \pm 0.00^{*}$ & $15.30 \pm 0.00^{* * *}$ \\
\hline & 1000 & $38.00 \pm 1.15^{* *}$ & $4.20 \pm 0.12$ & $9200.00 \pm 0.00$ & $210.00 \pm 0.00^{* *}$ & $14.80 \pm 0.12^{* * *}$ \\
\hline & 1600 & $40.00 \pm 0.58^{* * *}$ & $4.40 \pm 0.00^{* *}$ & $8800.00 \pm 0.00$ & $200.00 \pm 1.15$ & $16.13 \pm 0.07^{* * *}$ \\
\hline & 2900 & $40.00 \pm 0.00^{* * *}$ & $4.80 \pm 0.12^{* * *}$ & $8600.00 \pm 0.00$ & $185.00 \pm 0.00^{* * *}$ & $15.10 \pm 0.12^{* * *}$ \\
\hline & 5000 & $46.00 \pm 1.15^{* * *}$ & $4.60 \pm 0.12^{* *}$ & $8000.00 \pm 0.00$ & $190.00 \pm 1.15^{* * *}$ & $14.60 \pm 0.12^{* * *}$ \\
\hline \multirow[t]{7}{*}{ RT3 } & Control & $33.00 \pm 1.15$ & $3.80 \pm 0.00$ & $7800.00 \pm 0.00$ & $200.00 \pm 0.00$ & $11.90 \pm 0.06$ \\
\hline & 10 & $34.60 \pm 0.12$ & $3.93 \pm 0.09$ & $8000.00 \pm 0.00$ & $180.00 \pm 1.15^{* * *}$ & $12.4 \pm 0.12$ \\
\hline & 100 & $36.00 \pm 1.15$ & $4.20 \pm 0.12^{*}$ & $8100.00 \pm 0.00$ & $185.00 \pm 0.58^{* * *}$ & $12.80 \pm 0.12$ \\
\hline & 1000 & $37.00 \pm 0.00^{*}$ & $4.10 \pm 0.12$ & $8400.00 \pm 0.00$ & $200.00 \pm 0.00$ & $14.20 \pm 0.12^{* * *}$ \\
\hline & 1600 & $42.00 \pm 1.15^{* * *}$ & $4.80 \pm 0.12^{* * *}$ & $9100.00 \pm 0.00$ & $210.00 \pm 2.89^{* *}$ & $15.80 \pm 0.00^{* * *}$ \\
\hline & 2900 & $46.00 \pm 0.00^{* * *}$ & $5.10 \pm 0.12^{* * *}$ & $8800.00 \pm 0.00$ & $195.00 \pm 1.95$ & $13.60 \pm 0.12^{* *}$ \\
\hline & 5000 & $44.50 \pm 0.12^{* * *}$ & $4.90 \pm 0.06^{* * *}$ & $8600.00 \pm 0.00$ & $185.00 \pm 1.85^{* * *}$ & $14.00 \pm 0.58^{* * *}$ \\
\hline \multirow[t]{7}{*}{ LB1 } & Control & $33.00 \pm 0.17$ & $3.77 \pm 0.33$ & $7800.00 \pm 0.00$ & $201.33 \pm 0.88$ & $11.83 \pm 0.07$ \\
\hline & 10 & $33.00 \pm 0.58$ & $3.53 \pm 0.04^{*}$ & $8400.00 \pm 0.00$ & $200.67 \pm 0.33$ & $12.40 \pm 0.03^{*}$ \\
\hline & 100 & $33.00 \pm 0.00$ & $3.80 \pm 0.00$ & $8600.00 \pm 0.00$ & $180.00 \pm 0.00^{* * *}$ & $11.80 \pm 0.01$ \\
\hline & 1000 & $36.33 \pm 0.41^{* * *}$ & $4.53 \pm 0.04^{* * *}$ & $9200.00 \pm 0.00$ & $196.33 \pm 0.88^{* *}$ & $14.20 \pm 0.05^{* * *}$ \\
\hline & 1600 & $37.67 \pm 0.33^{* * *}$ & $4.20 \pm 0.06^{* * *}$ & $6400.00 \pm 0.00$ & $220.00 \pm 0.00^{* * *}$ & $15.96 \pm 15.78^{* * *}$ \\
\hline & 2900 & $34.37 \pm 0.54$ & $3.80 \pm 0.07$ & $8800.00 \pm 0.00$ & $208.67 \pm 0.88^{* * *}$ & $15.17 \pm 0.09 * * *$ \\
\hline & 5000 & $33.33 \pm 0.44$ & $3.63 \pm 0.03$ & $7600.00 \pm 0.00$ & $199.67 \pm 0.88$ & $13.47 \pm 0.06^{* * *}$ \\
\hline
\end{tabular}

Values are presented as mean \pm Standard error of mean, $\mathrm{n}=3 .{ }^{*} \mathrm{p}<0.05$ : Significantly different from control. ${ }^{* *} \mathrm{p}<0.01$ : Significantly different from control. ${ }^{* * *} \mathrm{p}<0.0005$ : Significantly different from control. 
Table 3: Effects of the graded doses on biochemical parameters of rats

\begin{tabular}{|c|c|c|c|c|c|c|c|}
\hline Treatment & $\begin{array}{l}\text { Dose } \\
\text { (mg/kg) }\end{array}$ & TP (g/dl) & $\begin{array}{l}\text { Creatinine } \\
\text { (mg/dl) }\end{array}$ & AST (IU/L) & ALT (IU/L) & ALP (IU/L) & $\begin{array}{l}\text { Albumin } \\
\text { (g/dl) }\end{array}$ \\
\hline \multirow[t]{7}{*}{ RT1 } & Control & $3.70 \pm 0.12$ & $3.70 \pm 0.14$ & $46.00 \pm 0.00$ & $42.00 \pm 0.00$ & $29.00 \pm 0.58$ & $2.00 \pm 0.00$ \\
\hline & 10 & $2.10 \pm 0.12^{* * *}$ & $3.43 \pm 0.07$ & $42.00 \pm 1.15$ & $40.67 \pm 1.76$ & $24.00 \pm 1.15^{* *}$ & $2.30 \pm 0.06^{*}$ \\
\hline & 100 & $2.90 \pm 0.06^{* * *}$ & $3.50 \pm 0.12$ & $33.60 \pm 0.35$ & $41.00 \pm 1.15$ & $27.00 \pm 0.00$ & $1.90 \pm 0.06$ \\
\hline & 1000 & $4.00 \pm 0.12$ & $3.80 \pm 0.12$ & $21.20 \pm 0.00^{* *}$ & $45.00 \pm 1.15$ & $26.00 \pm 0.58^{*}$ & $2.50 \pm 0.12^{* * *}$ \\
\hline & 1600 & $4.20 \pm 0.16^{*}$ & $2.70 \pm 0.00^{* * *}$ & $45.10 \pm 0.12$ & $51.00 \pm 0.58$ & $31.00 \pm 1.15$ & $3.10 \pm 0.03^{* * *}$ \\
\hline & 2900 & $3.90 \pm 0.06$ & $3.30 \pm 0.12$ & $20.80 \pm 8.90^{* *}$ & $48.00 \pm 1.15$ & $29.85 \pm 0.18$ & $4.80 \pm 0.12^{* * *}$ \\
\hline & 5000 & $4.10 \pm 0.06$ & $4.20 \pm 0.03^{*}$ & $37.47 \pm 0.07$ & $52.00 \pm 1.15$ & $32.00 \pm 0.58^{*}$ & $3.60 \pm 0.00^{* * *}$ \\
\hline \multirow[t]{7}{*}{ RT2 } & Control & $3.70 \pm 0.09$ & $3.70 \pm 0.06$ & $18.40 \pm 13.80$ & $42.00 \pm 0.58$ & $29.00 \pm 0.58$ & $2.00 \pm 0.01$ \\
\hline & 10 & $3.40 \pm 0.12$ & $3.50 \pm 0.03$ & $38.00 \pm 0.58$ & $40.00 \pm 0.58$ & $26.00 \pm 0.58$ & $1.90 \pm 0.01$ \\
\hline & 100 & $3.90 \pm 0.00$ & $3.80 \pm 0.00$ & $43.00 \pm 1.15^{*}$ & $43.00 \pm 0.58$ & $27.85 \pm 1.00$ & $2.20 \pm 0.00^{* *}$ \\
\hline & 1000 & $4.20 \pm 0.14^{*}$ & $3.60 \pm 0.12$ & $48.00 \pm 0.00^{* *}$ & $44.00 \pm 0.01$ & $32.00 \pm 1.15$ & $2.50 \pm 0.03^{* * *}$ \\
\hline & 1600 & $3.80 \pm 0.12$ & $4.00 \pm 0.12^{*}$ & $52.00 \pm 1.15^{* *}$ & $39.00 \pm 0.58^{* *}$ & $30.00 \pm 0.58$ & $2.90 \pm 0.02^{* * *}$ \\
\hline & 2900 & $4.00 \pm 0.06$ & $3.90 \pm 0.00$ & $56.00 \pm 0.00^{* *}$ & $47.00 \pm 0.73^{* * *}$ & $34.00 \pm 0.58^{* *}$ & $2.90 \pm 0.09^{* * *}$ \\
\hline & 5000 & $3.90 \pm 0.09$ & $4.10 \pm 0.06^{* *}$ & $49.00 \pm 0.58^{* *}$ & $51.00 \pm 0.58^{* * *}$ & $37.00 \pm 0.58^{* *}$ & $2.70 \pm 0.01^{* * *}$ \\
\hline \multirow[t]{7}{*}{ RT3 } & Control & $3.70 \pm 0.03$ & $3.70 \pm 0.01$ & $46.00 \pm 0.35$ & $42.00 \pm 0.20$ & $29.00 \pm 0.58$ & $2.00 \pm 0.06$ \\
\hline & 10 & $3.60 \pm 0.01$ & $3.30 \pm 0.06^{* *}$ & $40.00 \pm 0.58^{* * *}$ & $42.00 \pm 1.15$ & $27.00 \pm 0.17$ & $2.20 \pm 0.12$ \\
\hline & 100 & $3.90 \pm 0.06^{*}$ & $3.80 \pm 0.06$ & $44.00 \pm 0.56$ & $38.00 \pm 0.58$ & $30.00 \pm 0.00$ & $1.87 \pm 0.09$ \\
\hline & 1000 & $3.90 \pm 0.02^{*}$ & $3.70 \pm 0.06$ & $47.13 \pm 0.59$ & $41.00 \pm 0.58$ & $28.00 \pm 1.15$ & $2.30 \pm 0.01^{*}$ \\
\hline & 1600 & $4.10 \pm 0.06^{* * *}$ & $3.90 \pm 0.09$ & $48.00 \pm 0.58$ & $45.00 \pm 0.00$ & $33.00 \pm 0.24^{* *}$ & $2.50 \pm 0.01^{* * *}$ \\
\hline & 2900 & $4.30 \pm 0.01^{* * *}$ & $4.00 \pm 0.01^{* * *}$ & $51.00 \pm 0.58^{* * *}$ & $44.00 \pm 1.15$ & $32.00 \pm 0.00^{* *}$ & $2.40 \pm 0.00^{* *}$ \\
\hline & 5000 & $5.10 \pm 0.06^{* * *}$ & $4.20 \pm 0.06^{* * *}$ & $49.00 \pm 0.58^{* *}$ & $47.00 \pm 0.12$ & $35.00 \pm 0.58^{* * *}$ & $2.60 \pm 0.01^{* * *}$ \\
\hline \multirow[t]{7}{*}{ LB1 } & Control & $3.70 \pm 0.00$ & $3.70 \pm 0.04$ & $45.67 \pm 0.44$ & $42.00 \pm 0.58$ & $29.00 \pm 0.00$ & $2.00 \pm 0.12$ \\
\hline & 10 & $3.40 \pm 0.10$ & $3.53 \pm 0.07$ & $44.00 \pm 0.00$ & $41.00 \pm 0.58$ & $29.00 \pm 0.58$ & $1.80 \pm 0.02$ \\
\hline & 100 & $3.80 \pm 0.06$ & $3.80 \pm 0.06$ & $47.00 \pm 0.58$ & $39.00 \pm 0.58^{* *}$ & $32.00 \pm 0.58^{* *}$ & $1.79 \pm 0.04$ \\
\hline & 1000 & $3.90 \pm 0.08$ & $3.90 \pm 0.06^{*}$ & $48.33 \pm 0.15^{* *}$ & $43.00 \pm 0.00$ & $28.00 \pm 0.58$ & $2.07 \pm 0.07$ \\
\hline & 1600 & $4.10 \pm 0.06^{* *}$ & $3.80 \pm 0.01$ & $51.00 \pm 0.00^{* * *}$ & $43.00 \pm 0.29$ & $30.00 \pm 0.00$ & $2.60 \pm 0.06^{* * *}$ \\
\hline & 2900 & $3.80 \pm 0.05$ & $3.97 \pm 0.01^{* *}$ & $50.00 \pm 0.58^{* * *}$ & $45.00 \pm 0.58^{* * *}$ & $33.00 \pm 0.58^{* * *}$ & $2.40 \pm 0.06^{* *}$ \\
\hline & 5000 & $4.30 \pm 0.12^{* * *}$ & $4.00 \pm 0.01^{* *}$ & $51.00 \pm 0.58^{* * *}$ & $49.00 \pm 0.58^{* * *}$ & $35.00 \pm 0.72^{* * *}$ & $2.90 \pm 0.06^{* * *}$ \\
\hline
\end{tabular}

Values are presented as mean \pm Standard error of mean, $\mathrm{n}=3 .{ }^{*} \mathrm{p}<0.05$ : Significantly different from control. ${ }^{* *} \mathrm{p}<0.01$ : Significantly different from control. ${ }^{* * *} \mathrm{p}<0.0005$ : Significantly different from control.

Key

AST: Aspartate amino transferase.

ALTS: Alanine amino transferase

ALP: Alkaline phosphate..TP : Total protein 
Table 4: Effects of the graded doses of the metabolites on immunological parameters of mice.

\begin{tabular}{|c|c|c|c|c|c|c|}
\hline Treatment & $\begin{array}{l}\text { Dose } \\
\text { (mg/kg) }\end{array}$ & Neutrophil (\%) & Lymphocytes (\%) & Eosinophil & Monocytes & Basophil \\
\hline \multirow[t]{7}{*}{ RT1 } & Control & $58.00 \pm 0.16$ & $33.67 \pm 0.33$ & $2.00 \pm 0.00$ & - & - \\
\hline & 10 & $62.00 \pm 0.35^{* * *}$ & $32.00 \pm 0.58$ & $2.00 \pm 0.00$ & - & - \\
\hline & 100 & $60.00 \pm 0.58^{*}$ & $30.00 \pm 0.00^{* * *}$ & $2.00 \pm 0.00$ & - & - \\
\hline & 1000 & $62.33 \pm 0.35^{* * *}$ & $30.00 \pm 0.58^{* * *}$ & $0.00 \pm 0.00^{* *}$ & - & - \\
\hline & 1600 & $56.33 \pm 0.31^{*}$ & $36.00 \pm 0.58^{*}$ & $1.33 \pm 0.70$ & - & - \\
\hline & 2900 & $63.67 \pm 0.42^{* * *}$ & $44.00 \pm 0.58^{* * *}$ & $1.33 \pm 0.70$ & - & - \\
\hline & 5000 & $70.00 \pm 0.58^{* * *}$ & $42.00 \pm 0.17^{* * *}$ & $0.00 \pm 0.00^{* *}$ & - & - \\
\hline \multirow[t]{7}{*}{ RT2 } & Control & $58.00 \pm 0.58$ & $33.33 \pm 0.57$ & $2.00 \pm 0.00$ & - & - \\
\hline & 10 & $58.33 \pm 0.18$ & $34.00 \pm 0.00$ & $1.33 \pm 0.67$ & - & - \\
\hline & 100 & $62.00 \pm 0.17^{* * *}$ & $36.00 \pm 0.58^{*}$ & $0.00 \pm 0.00$ & - & - \\
\hline & 1000 & $64.00 \pm 0.58^{* * *}$ & $33.00 \pm 0.58$ & $2.00 \pm 0.00$ & - & - \\
\hline & 1600 & $72.00 \pm 0.29^{* * *}$ & $35.00 \pm 0.29$ & $1.33 \pm 0.67$ & - & - \\
\hline & 2900 & $60.00 \pm 0.58^{* * *}$ & $40.00 \pm 0.58^{* * *}$ & $0.00 \pm 0.00$ & - & - \\
\hline & 5000 & $61.00 \pm 0.06^{*}$ & $43.00 \pm 0.11^{* * *}$ & $1.33 \pm 1.33$ & - & - \\
\hline \multirow[t]{7}{*}{ RT3 } & Control & $58.00 \pm 0.58$ & $33.67 \pm 0.18$ & $2.00 \pm 0.00$ & - & - \\
\hline & 10 & $60.00 \pm 0.00 *$ & $32.00 \pm 0.58$ & $2.00 \pm 0.00$ & - & - \\
\hline & 100 & $60.00 \pm 0.58^{*}$ & $56.00 \pm 0.00^{* * *}$ & $1.33 \pm 0.67$ & - & - \\
\hline & 1000 & $62.00 \pm 0.12^{* * *}$ & $44.00 \pm 0.41^{* * *}$ & $1.33 \pm 0.67$ & - & - \\
\hline & 1600 & $60.00 \pm 0.58^{*}$ & $41.33 \pm 0.33^{* * *}$ & $1.33 \pm 1.33$ & - & - \\
\hline & 2900 & $66.00 \pm 0.17^{* * *}$ & $38.00 \pm 0.58^{* * *}$ & $0.00 \pm 0.00$ & - & - \\
\hline & 5000 & $62.00 \pm 0.58^{* * *}$ & $40.00 \pm 0.58^{* * *}$ & $2.00 \pm 0.00$ & - & - \\
\hline \multirow[t]{7}{*}{ LB1 } & Control & $58.00 \pm 0.58$ & $34.00 \pm 0.00$ & $2.00 \pm 0.00$ & - & - \\
\hline & 10 & $57.00 \pm 0.06$ & $34.00 \pm 0.06$ & $1.33 \pm 0.67$ & - & - \\
\hline & 100 & $58.67 \pm 0.88$ & $32.00 \pm 0.87$ & $1.33 \pm 0.67$ & - & - \\
\hline & 1000 & $58.00 \pm 0.35$ & $36.00 \pm 0.12$ & $1.33 \pm 0.67$ & - & - \\
\hline & 1600 & $61.00 \pm 0.58^{* *}$ & $40.00 \pm 0.58^{* * *}$ & $2.00 \pm 0.00$ & - & - \\
\hline & 2900 & $64.00 \pm 0.12^{* * *}$ & $44.00 \pm 0.00^{* * *}$ & $2.67 \pm 1.33$ & - & - \\
\hline & 5000 & $60.00 \pm 0.58$ & $52.10 \pm 0.84^{* * *}$ & $2.67 \pm 1.33$ & - & - \\
\hline
\end{tabular}

Values are presented as mean \pm Standard error of mean, $n=3 .{ }^{*} p<0.05$ : Significantly different from control. ${ }^{* *} \mathrm{p}<0.01$ : Significantly different from control. ${ }^{* * *} \mathrm{p}<0.0005$ : Significantly different from control.

\section{DISCUSSION}

Tables 1- 4 present the various results of the acute oral toxicity studies of various doses of endophytic fungal metabolites on mice.

Many researchers have reported the acute oral toxicity results of their endophytic extract on mice. In a more recent study, it has been noted that chanoclavine, a metabolite often extracted from endophytes recorded $L_{50}>2000$. [22] Similarly, ethyl acetate extract from Cochliobolus spicifer was reported to have no toxic lesions on the kidney and liver of sacrificed mice. [23] In the present study some of the animals showed early sign of toxicity which later resolved within the first 2 hours. There was no mortality recorded after 24 hours of observation. In figures 1-4, sections of the liver collected from the mice administered with the crude extract from different fungal isolates were shown. There was no observed lesion or any sign of inflammation in all the liver tissues. This has further given credence to the folkloric use of this plant in treating hepatitis. [24] The implication of these observations was that the median lethal dose $\left(\mathrm{LD}_{50}\right)$ was greater than the given dose of $5000 \mathrm{mg} / \mathrm{kg}$.

In Table 2, the results of the haematological parameters studied were shown. The PCV, RBC and $\mathrm{Hb}$ recorded marked increase $(p<0.05)$ relative to the control in RT1 metabolite. This implies that the metabolites had a component that could induce erythropoiesis/haematopoieses. On the other hand, WBC and platelets showed an inverse relationship with increase in the dose of the metabolite. This finding is of great pharmaceutical importance in developing anticoagulants/ haematostatic agent as well as immunomodulatory drugs. 
Again, metabolites from other root isolates increased all the tested hematological parameters except the platelet. Similarly, significant differences $(\mathrm{p}<0.05)$ in haematological and biochemical parameters as well as organ-to-body weight ratios were detected between the 60 and $120 \mathrm{mg} \mathrm{kg}^{-1}$ groups in a separate study. [25] It is the belief of this study that further investigations of these root isolates would yield novel compound that would be useful in the management of blood related disease.

The leaf-blade isolates did not demonstrate dose dependent activity. This implies that higher doses of the extract may not elicit further hematological response. In observing the biochemical parameter as shown in Table 3, metabolites from RT1 isolate, caused significant increase in total protein and albumin which has bearing with the animal's immunogenic response to allergens. The relative increase observed in AST, ALT, ALP and the decline in creatinine is an indication of the hepato-protective properties of this fungal extract. Similarly, metabolites from the other three isolates showed varied effect on the biochemical parameter. Table 4 presents dose dependent immune potentiating capacities of the various extract from the endophytic fungal isolates.

\section{CONCLUSION}

Most parts of Annona senegalensis used in traditional medicine practices are ingested. Therefore, acute oral toxicity study of crude extract from endophytic fungi isolated from the plant parts need to be undertaken. The various doses of the extract administered to the mice in groups were observed within $24 \mathrm{~h}$ as described by Lorke. Data generated from the present study showed that there was no mortality or any histological defect in the liver of the experimental animals. This implies that the extract is relatively safe in humans with $\mathrm{LD}_{50}>5000 \mathrm{mg} / \mathrm{kg}$. Again, the observed increase in PCV, HB, RBC and other hematological parameters showed that the metabolite has hematopoietic properties. The immunological parameter tested showed significant increase in neutrophils and lymphocytes relative to the control whereas eosinophils remained at $2 \%$ for both control and crude extract in all the fungal isolates. This study, no doubt has provided a baseline toxicological data on the crude extract of endophytic fungi isolated from Annona senegalensis Pers. However, in the hope of establishing the purity and chronic toxicities of this endophytic fungal extract, further study is highly recommended.

\section{CONFLICT OF INTEREST}

The authors have no conflict of interest to declare.

\section{REFERENCES}

1. Umamaheswar RO, Chinna EM. Single dose oral toxicity study of ethanolic extract from inflorescence of Casuarina equisetifolia in Wistar rats. Journal of Drug Delivery and Therapeutics, 2018; 8(6-s):44-47.

2. Sheah Y G, Jin H C, Yin YT, Hip SY, Chun W H. Acute Ora Toxicity Study of Aquilaria Crassna and A-Tocopherol In Mice. IJPSR, 2016; 7 (4):1456-1461.

3. Kale OE, Awodele O, Akindele AJ. Subacute and subchronic oral toxicity assessments of Acridocarpus smeathmannii (DC.) Guill. \& Perr. root in Wistar rats, Toxicol. Rep.2019; 6:161175.

4. Ahmad L, He Y, Hao J C, Semotiuk A, Liu QR, Mazari, P. Toxic pyrrolizidine alkaloids provide a warning sign to overuse of the ethnomedicine Arnebia benthamii, J. Ethnopharmacol. 2018; 210:88-94.

5. Kpemissia M, Metowogoa K, Melilaa M, Veerapurc V P, Negrub M., Taulescub M., Adrian-Valentin P, Suhasc DS, Puneethc
TA,Vijayakumarc S, Eklu-Gadegbekua K, Aklikokoua K. Acute and subchronic oral toxicity assessments of Combretum micranthum (Combretaceae) in Wistar rats Toxicology Reports 2020; 7:162-168

6. Potchoo Y, Richard D, Sakie E, Guissou IP, Kini F, Yaro B. Comparative Phytochemical Content of Leaves Extract of two Annona Senegalensis Pers: The one from Togo and the other Originates from Burkina Faso. Journal of Biological Sciences 2008; 8(3):577-583.

7. Koto-te-Nyiwa N, Emmanuel LM., John LB, Ruphin DD, Colette MA, Pius TM. A mini-review of the Pharmacognosy and Phytochemisry of a Tropical Medicinal Plant. Annona Senegalensis Pers. Tropical Plant Research 2017; 4(1):168175.

8. Gadaleta D , Vuković1 K., Toma1 C, Lavado1 GJ, Karmaus A.L, Mansouri K., Kleinstreuer NC, Benfenati E, Roncaglioni, A. SAR and QSAR modeling of a large collection of LD50 rat acute oral toxicity data Cheminform 2019; 11:58

9. OECD Test No. 425: acute oral toxicity: up-and-down procedure,OECD guidelines for the testing of chemicals, section 4, OECD Publishing, Paris. 2008.

10. Kennedy GL Jr, Graepel GJ. Acute toxicity in the rat following either oral or inhalation exposure. Toxicol Lett 1991; 56(3):317-326.

11. Garry S, Diasy B, Uvidello C. The Biological Promise of Microbial Endophyte and their Natural Products. Plant Pathology Journal 2005; 4(2):161-176.

12. Khaled A S, Waill A E, Ahmed MT, Ahmed AE, Tahany M Abdel-R, Ahmed I.E and Eman F A. Antiviral and Antioxidant Potential of Fungal Endophytes of Egyptian Medicinal Plants. Fermentation 2018; 4, 49.

13. Tan R, Zou W. Endophytes: A rich source of functional metabolites. Nat. Prod. Rep. 2001; 18:448-459.

14. Herrera H, Sanhueza T, Alžb̌eta Novotná, Trevor C C, Cesar A. Isolation and identification of endophytic bacteria from mycorrhizal tissues of terrestrial orchids from southern Chile. Diversity 2020; 12(55):1-12.

15. Lorke, D. "A new approach to practical acute toxicity testing," Archives of Toxicology, 1983; 54(4):275-287,

16. Okezie MU, Eze P M, Okoye FBC, Ikegbunam MN, Ugwu MC, Esimone CO. Secondary Metabolites from an endophytic fungus of Vernonia amygdalina. African Journal of Pharmaceutical Research and Development. 2017; 9 (1):24-26.

17. Simth BJ, Black LL. Morphological, cultural and pathogenic variation among Colletotrihum species isolated from strawberry. Plant Diseases 1990; 74:69-67.

18. Sofowora, A. Medicinal Plants and Traditional Medicine in Africa, Spectrum Books Limited, Ibadan, Nigeria 1993 P 3445.

19. Ochei J, Kolhatkar A. Medical laboratory science: theory and practice. Tata McGraw-Hill Publishing Company Limited, new Delhi.2007; PP 265-287.

20. Randox laboratory limited. Manual/RX Monza. 55 Diamond Road Crumlin, County Antrim United Kingdom.2014; PP. 1-10.

21. Cheesbrough M. District laboratory practice in tropical countries. Cambridge University Press, United kingdom. 2000; Pp 296 - 327.

22. Sarah CF, John SM, Jan MS, Sweta B. Toxicity Studies of Chanoclavine in Mice. Toxins 2019; 11(249):1-11

23. Abutaha N, AL-Zharani M, AL-Mekhlafi FA, AL-Tamimi J, Mashaly AMA, Wadaan M A. Acute and Subacute Toxicity of Ethyl Acetate Fraction of Cochliobolus spicifer (Nelson) isolated from Phoenix dactylifera(Linnaeus) on Balb/c Mice. Res. J. Biotech. 2017; 12(4) 2-6.

24. Samuel EO, Edifofon A., Omolola TF, Kevwe BE, Oluyemisi FK. Annona senegalensis Person (Annonoaceae): A review of its ethnomedicinal uses, biological activites and phytocompound. Journal of Pharmacognosy and Phytochemistry 2016; 5(2):211-219.

25. Xiao W, Wang X, Wang C, Wang M, Fei C, Zhang L, Xue F, Wang G, Zhang K. Acute and 30-day oral toxicity studies of a novel coccidiostat - ethanamizuril, Toxicology Research, 2019; 8(5):686-695 